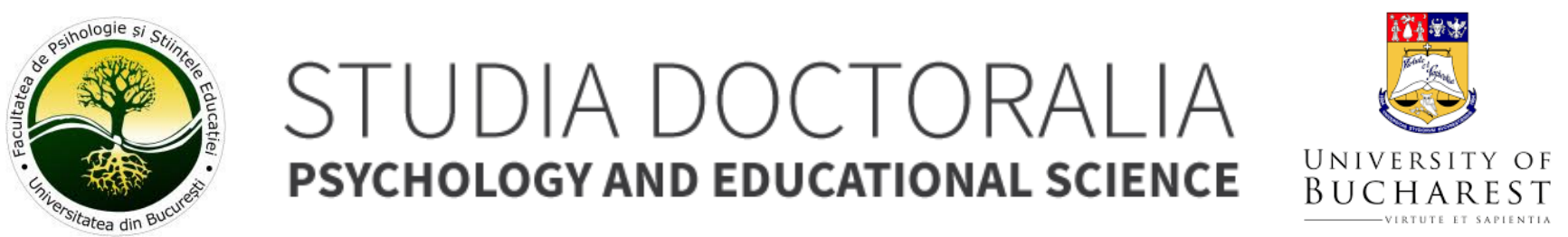

\title{
The role of cognitive schemas in the relationship between attachment style and emotional intelligence \\ Elena Morena Scarlat \\ University of Bucharest
}

\section{ARTICLE INFO}

\author{
Article history \\ Received 02-February-2021 \\ Accepted 10-March-2021 \\ Available online 01-May-2021
}

This article should be cited as: Scarlat, E. M. (2021). The role of cognitive schemas in the relationship between attachment style and emotional intelligence. Studia Doctoralia. Psychology and Educational Science, 12(1), 5469. https://doi.org/10.47040/sd0000088

This is an open access article under the CC BY license (http://creativecommons.org/licenses/by/4.0/).

Corresponding author at: University of Bucharest, Department of Psychology, 90 Panduri Av, Bucharest, RO.

Tel.: +40 (0) 31-425.34.45

E-mail address: morenascarlat99@gmail.com

\section{ABSTRACT}

The current study focuses on the idea that the relationship between attachment styles and emotional intelligence can be influenced by cognitive schemas. It is well known that the first interaction between the child and his mother lays the foundations of attachment. The extent to which it develops guides the individual throughout his life making him responsible for his own actions and decisions. In this way studying the three variables becomes the main objective of the study. The data were collected on an online form, using the snowball method by which subjects were able to share the questionnaire to acquaintances to gather a larger number of people. The study was attended by 281 people aged between 18 to 40 years, $M=21.98, S D=4.10$, of which, 52 were males (18.50\%) and 229 females (81.50\%), 134 were single (47.69\%) and 147 were in a relationship (52.31\%), 48 people come from single-parent families (17.08\%) and 233 come from two-parent families (82.92\%). The results were as expected, secure attachment constitutes a significant positive predictor of emotional intelligence while the anxious attachment was a significant negative predictor of emotional intelligence. The results also showed that avoidant attachment would be a significant positive predictor of emotional intelligence. Following the results it was observed that there is a mediation between cognitive schema and the relationship between attachment styles and emotional intelligence. The secure attachment style was significantly negatively associated with all three types of schemas as expected.

Keywords: attchment styles, emotional intelligence, cognitive schemas 


\section{INTRODUCTION}

Attachment style plays an important role in everybody's life being present in that from the first moments. The connection formed at birth between mother and child can lay the foundations of a style of attachment that will guide and develop the person preferably in the best possible way. The extent to which it evolves will make the person responsible for their own actions and decisions throughout life. Several researchers have shown that a person's attachment style is closely linked to both emotional intelligence and cognitive schemas.

Emotional intelligence is also an important aspect in a person's life helping to better understand the inner world, but also the outer world. Over time many researchers have noticed the importance of attachment style but also emotional intelligence, which is why they began to study the relationship between them. Many results say that a secure attachment style determines a high level of emotional intelligence and an anxious attachment leads to a low level of emotional intelligence.

There is also an interest among researchers in the relationship between cognitive schemas and attachment style. Cognitive schemas are responsible for how people build current experiences based on previous ones helping the individual to guide themselves as well as what is surrounding it. The researcher's results say that a healthy attachment style will lead to the use of fewer cognitive schemas while a dysfunctional attachment style will have a higher tendency to use cognitive schemas.

Starting from the attachment style and its importance in terms of emotional intelligence, but also cognitive schemas the current study aims to study the relationship between the three variables. The central motivation of the study is to observe how the relationship between attachment styles and emotional intelligence can be influenced by the use of dysfunctional cognitive schemas like emotional deprivation, failure, and seeking approval schemas.

\section{Attachment type}

Attachment plays an important role in a person's life, being a basic emotional connection, as John Bowlby (1982) states. The development of a secure attachment style guides the future individual towards a healthy lifestyle and the choice of the most favorable relationships (Mikulincer \& Shaver, 2012a). The protection offered by the mother at birth, and the security provided by an attachment figure during child development, contribute to a type of attachment that will follow the individual throughout his lifetime (Mikulincer \& Shaver, 2012b). Thus, the development of a type of secure attachment and trust established relationship with parents is an area of interest in child development and adult (Bosmans et al., 2020).

A person's attachment style describes the way he behaves in relationships with others, but also with himself. It has a special importance on establishing trust in the relationship with others the fear of abandonment or rejection as well as in the person's preference for loneliness, distance or self-sufficiency (Meyer \& Pilkonis, 2001). Formed in response to the first events that the individual goes through with an attachment figure, this connection leaves its mark on the way the person sees the world, on the relationship with those around him, but also with himself (Mikulincer \& Shaver, 2009). The literature emphasizes the idea that the lack of an attachment figure, especially the maternal one, during childhood (until the age of three), leads to the development of a dysfunctional attachment (Lieberman \& Zeanah, 1995) like anxiety, anger or fear of abandonment (Lyons-Ruth \& Jacobvitz, 2008). A secure relationship with parents, carefully consolidated in childhood, brings the child into the position where he is sure that he can trust them (Theisen et al., 2018). Also, secure attachment is manifested by a high level of closeness to others, as well as a high sense of confidence in yourself and in others, but also in an optimal development of the individual (Kawamoto, 2020).

People with avoidant attachment will tend to maintain a social distance from partners and those with anxious attachment will always be concerned about the availability of the partner in times that seem more difficult (Mikulincer \& Shaver, 2007). An avoidant attachment is characterized by a distance from people and a low sense of security, and an anxious attachment is characterized by a high need for closeness to others, having a sense of security as low as avoidant type (Greenberg et al., 1983). A person with a secure attachment type feels comfortable talking about his feelings, beliefs or attitudes, while insecure attachment types seem to show the same insecurity in social skills, facing difficulties in expressing their views, beliefs, feelings and encountering a barrier in their maturation process (DiTommaso et al., 2003).

A secure attachment style is also considered a predictor of resilience, leading to better management of stress and problematic situations (Hawkins et al., 2007; Terzi, 2013; Wei et al., 2003). Moreover, people with such an attachment have a higher control of negative emotional states caused by stress (Mikulincer \& Florian, 1995) and they adapt more quickly to negative states that may occur (McCarthy et al., 2001). In such situations acceptance strategies built during childhood act as a protective factor thus increasing resilience (Terzi, 2013).

Dysfunctional attachment styles will use denial when they face with stressful situations remaining stuck in those events (Janssen et al., 2002; Lopez et al., 2001). Along with denial used as a negative avoidance behavior (Lussier et al., 1997; Howard \& Medway, 2004), people with dysfunctional attachment will find refuge to overcome stressful or 
problematic situations in alcohol and drug use (Caltabiano \& Grosset, 2009), manifesting states of anxiety, depression or even a low level of well-being (Scott \& Cordova, 2002).

\section{Emotional intelligence}

Emotional intelligence, an expression first used by Salovey and Mayer (1990) is defined as a subset of social intelligence involving the ability to observe both one's own and others' feelings and emotions, but also to be able to discriminate between them to guide a person's thinking and actions (Salovey \& Mayer, 1990). They define emotional intelligence as a set of four skills: perceiving, using, understanding, and managing emotions (Grewal \& Salovey, 2005) and providing brief characterizations to help them better understand concepts.

Emotional intelligence is also considered a theoretical construct that represents the ability to perceive, assimilate, understand and manage emotions (Doinita, 2015). This can be seen as a means of better guiding a person's mind and behavior, but also a much broader perspective of selfunderstanding (Ninivaggi, 2020).

Many studies demonstrate that a better expression of emotions and a more diverse nuance of them is due to a higher level of emotional intelligence. It was observed that it develops early in adolescence continues up to adulthood (Mayer et al., 1999).

Goleman (2012) observed differences between men and women and the predominant type of intelligence they have and tried to outline their behavior. It was found that men with a high level of general intelligence (IQ) have an interest in the intellectual field, are ambitious, productive, persevering, routine, but critical, inhibited, detached, cold, having difficulty expressing feelings. On the other hand, men who have a high level of emotional intelligence (EI) are balanced, cheerful, sociable and do not worry so often, can easily engage in tasks, take responsibility and take care of their relationships. Their emotional life is richer, being comfortable for them to open up to others or to other social relationships they encounter (Goleman, 2012).

Women with a high level of general intelligence (IQ) have confidence in their intellectual capacity, are fluent in the expression of thoughts, inevitably having a penchant for this field. They are more prone to introspection, are prone to anxiety, rumination or guilt, hesitant to express their anger in a direct way. In contrast women with a high level of emotional intelligence (EI) are more assertive, more lively, spontaneous, sociable, cope better with stressful situations, directly express their feelings, having a more positive opinion about their own person and being comfortable for them to be part of different social contexts (Goleman, 2012).

Goleman noted that emotional intelligence skills will more accurately predict a person's ability to hold a leadership position in the workplace than general intelligence or other skills, with emotional intelligence being very important in choosing, promoting, or developing a leader (Cherniss et al., 2006). A leader focused on staff needs will seek to maximize the positive emotions of the group and, implicitly, increase the level of emotional intelligence (Goleman et al., 2013), a necessary skill that differentiates high-performing teams from average teams in terms of performance (Goleman et al., 2002).

\section{Cognitive schemas}

Cognitive schemas are structures that are based on beliefs of a person developed early in life (Beck \& Weishaar, 2005). It is assumed that cognitive schemas appear and develop as a result of traumatic experiences lived during childhood and having their origin in the person's family or in the relationship with their caregivers (Ball, 2007; Young, 1994; Young et al., 2003; Shorey et al., 2012). Once formed they develop and follow the person throughout his life and are manifested by negative thoughts and deep feelings of worry, sadness and anxiety (Zeigler-Hill et al., 2011), being quite resistant to change (Ball, 2007).

Young and his colleagues (2003) observed that cognitive schemas can be triggered by a daily event or a simple mood, especially those with a strong emotional charge. When a schema is activated the significance it has on the person starts from his beliefs and it also interacts with other cognitive systems such as affection, motivation and behavior (Beck \& Haigh, 2014). These rigid patterns influence how people build their current experiences and relationships with others leading to the acquisition of new notions that help the individual to be guided both by himself and by what surrounds him (Kim \& Kishore, 2019). For people who have developed such beliefs, happiness or selfworth depend to a large extent on the approval of others and for them, partial failure is equivalent to complete failure (Dozois \& Beck, 2008).

They divided the 18 cognitive schemas into five categories: disconnection and rejection (abandonment, mistrust, emotional deprivation, defectiveness, social isolation), impaired autonomy and performance (dependence, vulnerability, enmeshment, failure), impaired limits (entitlement, insufficient self-control), otherdirectedness (subjugation, self-sacrifice, approval-seeking), overvigilance and inhibition (negativity, emotional inhibition, unrealistic standards, punitiveness) (Young, 1999; Young et al., 2003).

During adulthood cognitive schemas differ by gender. The results of several studies show that women are more likely to manifest a high level of schemas such as emotional deprivation, fear of abandonment, mistrust, social isolation, self-sacrifice and negativity, while men are more likely to manifest a high level of schemas such as failure, addiction, lack of self-control (Pellerone et al., 2017).

The present study focuses on three schemas (emotional deprivation, failure, approval-seeking) from different domains and tries to observe the relationships between them and other variables. 


\section{Emotional deprivation}

Emotional deprivation is the belief that one's desire for a normal degree of emotional support will not be adequately met by (Young, 1990; Yoosefi et al., 2010). As a cognitive schema which belongs to the separation and rejection domain, people who manifest it are more likely to come from families who are emotional unavailable, cold, distant or even abusive. This becomes a starting point for their insecurity about their own needs, considering that they will never be understood, listened to or shared with their feelings (PintoGouveia et al., 2006; Zeigler-Hill et al., 2011).

\section{Failure}

The cognitive schema of failure manifests itself on people through excessive awareness and misinterpretation of events, people tend to give all events a negative connotation (Leung \& Poon, 2001). For these people a minor failure translates into a major failure. The belief that one has failed, will inevitably fail, or is fundamentally inadequate relative to one's peers, in areas of achievement (school, career, sports) (Schmidt et al., 1995). Often involves beliefs that one is stupid, inept, untalented, ignorant, lower in status, less successful than others (Yoosefi et al., 2010). People who use the failure schema will focus on past or even present events in which they failed and will consider this scenario to be the only one possible (Petrocelli et al., 2001).

\section{Approval-seeking}

Seeking approval is the Excessive emphasis on gaining approval, recognition, or attention from other people, or fitting in, at the expense of developing a secure and true sense of self (Láng, 2015). One's sense of esteem is dependent primarily on the reactions of others rather than on one's own natural inclinations. People with this cognitive schema tend to not trust themselves (Ak et al., 2012), relying more on the opinions of others and trying to please them. Frequently results in major life decisions that are inauthentic or unsatisfying, or in hypersensitivity to rejection.

\section{Attachment style and emotional intelligence}

The relationship between attachment style and emotional intelligence has been studied over the years by several researchers. The literature provides evidence supporting that emotional intelligence is related to the warmth and support of parents (Mayer et al., 1999) but also that an attachment style can be a predictor of a person's emotional intelligence (Samadi et al., 2013). Thus, a secure attachment is often associated with a higher level of emotional intelligence (Kafetsios, 2004). The results also showed that a secure attachment style is closely related to a person's emotional intelligence, while the relationship between an anxious attachment style and emotional intelligence is negatively statistically significant (Kafetsios, 2004).

People raised in a safe environment, where they received the protection they needed, will have more developed interpersonal skills than those who did not grow up in such an environment, which is why the relationship between a secure attachment style and a high level of emotional intelligence is very close (Obeid et al., 2019). Taking into account the above, we establish the first hypothesis of our study:

H1. Attachment styles are significant predictors of emotional intelligence.

$\mathrm{H1a}$. The secure attachment style is a significant positive predictor of emotional intelligence.

$\mathrm{H} 1 \mathrm{~b}$. The avoidant attachment style is a significant negative predictor of emotional intelligence.

$\mathrm{H} 1 \mathrm{c}$. The anxious attachment style is a significant negative predictor of emotional intelligence.

\section{Attachment style and cognitive schemas}

Bowlby (1988) observed that a child who grew up with a secure attachment will develop positive beliefs about himself, while children raised in an environment where dysfunctional attachment was predominant will feel vulnerable, incapable and insecure about himself. Both a person's attachment and cognitive schemas are formed early in childhood and both depend largely on experiences with parents, caregivers, friends, or colleagues (Roelofs et al., 2013).

Bowlby (1988) and Young (1994) argued for the importance of childhood interaction with attachment figures, which contributes to the development of adaptive or maladaptive cognitive schemas (Harris \& Curtin, 2002). Thus, the representations formed through the prism of attachment relationships will later become cognitive schemas of the basic beliefs of an adult and will capture the way he relates to himself, others or the environment (Ingram, 2003).

Cognitive schemas can be influenced by the person's attachment style. For a secure attachment style, relationships with others will be more easily formed and the use of dysfunctional cognitive patterns will be greatly diminished compared to avoidant or anxious attachment styles (McLean et al., 2014). In this regard, several researchers have concluded that an avoidant or anxious attachment leads to a higher chance of developing a higher number of cognitive patterns (Ledoux et al., 2010). The results of a study show that there is an important link between insecure attachment (anxiety and avoidance) and the five major areas of cognitive schemas described by Young and colleagues (2003), with disconnection and rejection and other-directedness being more closely linked with anxious attachment style, while disconnection and rejection and impaired autonomy and performance being more closely related to avoidant attachment style (Bosmans et al., 2010). Through these schemas, avoidant attachment is characterized by experiences of rejection, independence and motivation not to show signs of weakness, while anxious attachment type is characterized by the need to gain and 
maintain an attachment figure, feeling inferior to it and becoming dependent on it (Mikulincer \& Shaver, 2007).

\section{Emotional intelligence and cognitive schemas}

The term emotional intelligence refers to the ability to perceive, assimilate, understand and manage emotions (Doinita, 2015). Studies have shown that a low level of emotional intelligence is associated with a higher probability to develop and use cognitive schemas (Ke \& Barlas, 2020). Once activated by events with a strong emotional impact, cognitive schemas can have both direct and indirect effects on the person, from anxiety, loneliness or depression, to conflicts and problems in interpersonal relationships (Esmali Kooraneh \& Amirsardari, 2015).

The relationship between cognitive schemas, attachment style and emotional intelligence

Cognitive schemas will follow the individual throughout life taking the form of negative thoughts and being quite resistant to change (Zeigler-Hill et al., 2011; Ball, 2007). Beliefs formed during the development of the individual will have an influence on the way of thinking and self-esteem (Beck, 1995; Beck et al., 1979; Clark et al., 1999; Kuiper \& Olinger, 1986). Cognitive schemas can be influenced to some extent by the person's attachment style, in the sense of amplifying or diminishing them. A secure attachment style will be noted by an ease in relating to others and by avoiding the use of dysfunctional cognitive patterns (McLean et al., 2014), while an avoidant or anxious attachment style will have a higher tendency to use dysfunctional cognitive schemas (Ledoux et al., 2010).

\section{METHODOLOGY}

\section{Participants and setting}

The participants of the study were 281 people aged between 18 to 40 years, $M=21.98, S D=4.10$, of which, 52 were males (18.50\%) and 229 females (81.50\%), 134 were single (47.69\%) and 147 were in a relationship (52.31\%), 48 people come from single-parent families (17.08\%) and 233 come from two-parent families (82.92\%). The form was distributed to people from the Faculty of Psychology and Educational Sciences, and later it was distributed on various social networks, such as Facebook and Instagram. The people who decided to participate in the study sent the form to other people, and thus the participants were varied, being part of other faculties, and also of different age categories. The data was collected between November 2020 and February 2021. They were informed of the academic and confidential purpose of the obtained data, being aware that they were not to be exposed to any physical or psychological risks.

\section{Instruments}

Attachment styles. Attachment Style Questionnaire, ASQ (Romaniello et al., 2015) was used to evaluate
Studies have shown that low emotional intelligence is associated with a higher likelihood of developing and using dysfunctional cognitive schemas (Ke \& Barlas, 2020), both emotional intelligence and the optimal emotional functioning of people can be deeply affected by their cognitive patterns and deep-rooted beliefs (Dimitriu \& Negrescu, 2015). However, the role of cognitive schemas in the relationship between attachment styles and emotional intelligence has not yet been followed, but we could deduce that cognitive schemas would have an impact on the relationship between attachment styles and emotional intelligence, based on the results discovered by other researchers between variables.

Cognitive schemas have been shown to have an effect on the development of emotional and behavioral problems, but also on the development of individuals (Fischer et al. 2016; Fouladi 2015; Wijk-Herbrink et al. 2018; Kaya \& Aydin, 2021). Thus, cognitive schemas can be considered to have a higher impact on anxious and avoidant attachment styles, as these two types tend to remain stuck in problematic or stressful situations (Janssen et al., 2002; Lopez et al., 2001). Even if the relationship between emotional intelligence and avoidant attachment is statistically significant (Kafetsios, 2004), which is supposed to help the individual to overcome that moment, cognitive schemas will amplify the states felt by the person.

Taking into account the above, we establish the second hypothesis of our study:

H2. Cognitive schemas mediate the relationship between attachment styles and emotional intelligence.

attachment styles. The questionnaire includes 40 items and measures three different attachment styles: secure, avoidant and anxious attachment, each evaluated on a 6point scale, in which 1 stand for "totally disagree" and 6 for "totally agree".

Emotional intelligence. Emotional Intelligence Questionnaire - skill (Mini Emotional Test and Workbook) (Ghyst et al., 2015) was used to evaluate emotional intelligence. The questionnaire contains 48 items and was used the Romanian version of the scale. The answers are given on a five-step Likert scale, in which 1 stand for "strong disagreement" and 5 for "strong agreement".

Cognitive schemas. Young Cognitive Schema Questionnaire - Short Form, YSQ-S3 (Young \& Brown, 2001) was used to measure cognitive schemas. The instrument comprises 114 items and measures 18 dysfunctional cognitive schemas. Of these, we measured only three of them, namely: Emotional Deprivation, Failure and Approval-Seeking, with a total of 24 items. The answers are given on a six-step Likert scale, in which 1 stand for "totally untrue to me" and 6 for "describes me perfectly". 


\section{RESULTS}

\section{Descriptive statistics}

Table 1. Descriptive statistics

\begin{tabular}{|c|c|c|c|c|c|c|c|c|c|c|}
\hline & $M$ & AS & $a$ & ATS & ATE & ATA & SDE & SES & SCA & $\mathrm{IE}$ \\
\hline ATS & 3.92 & .94 & .83 & 1 & & & & & & \\
\hline ATE & 2.96 & .85 & .68 & $-.53^{\text {t* }}$ & 1 & & & & & \\
\hline ATA & 3.38 & 1.13 & .90 & $-.65^{\text {t* }}$ & $.39^{+*}$ & 1 & & & & \\
\hline SDE & 16.25 & 4.49 & .61 & $-.39^{\text {t* }}$ & $.27^{7 *}$ & $.61^{* *}$ & 1 & & & \\
\hline SES & 12.81 & 4.76 & .66 & $-.50^{\text {** }}$ & $.41^{1 *}$ & $.61^{* *}$ & $.65^{* *}$ & 1 & & \\
\hline SCA & 41.06 & 15.08 & .90 & $-.56^{* *}$ & $.37^{* *}$ & $.74^{* *}$ & $.74^{* *}$ & $.79^{* *}$ & 1 & \\
\hline $\mathrm{IE}$ & 179.11 & 24.41 & .92 & $.62^{* *}$ & $-.20^{* * *}$ & $-.53^{\text {t* }}$ & $-.33^{\text {t* }}$ & $-.51^{\star *}$ & $-.53^{\text {t* }}$ & 1 \\
\hline
\end{tabular}

ATS - Secure attachment, ATE - Avoidant attachment, ATA - Anxious attachment, SDE - Emotional Deprivation schema, SES - Failure schema, SCA Approval-Seeking schema, IE - Emotional intelligence

\section{Hypotheses testing}

$\mathrm{H} 1$. Attachment styles are significant predictors of emotional intelligence.

$\mathrm{H} 1 \mathrm{a}$. The secure attachment style is a significant positive predictor of emotional intelligence.

$\mathrm{H} 1 \mathrm{~b}$. The avoidant attachment style is a significant negative predictor of emotional intelligence.
$\mathrm{H} 1 \mathrm{c}$. The anxious attachment style is a significant negative predictor of emotional intelligence.

For testing the first hypothesis a multiple linear regression analyzes were performed, having as predictors the three attachment styles and as dependent variable the emotional intelligence.

Table 2. Multiple regression analysis for attachment styles as predictors of emotional intelligence

\begin{tabular}{lccccc}
\hline & B & SE & Beta & t & p \\
\hline Secure attachment & 14.97 & 1.67 & .57 & 8.98 & .00 \\
Avoidant attachement & 5.85 & 1.53 & .20 & 3.83 & .00 \\
Axious attachment & -5.19 & 1.26 & -.24 & -4.11 & .00 \\
\hline
\end{tabular}

Dependent Variable: Emotional intelligence, $\mathrm{R}^{2}=.45$

As seen above, the three attachment styles are responsible for $45 \%$ of the variation of emotional intelligence, the regression equation being statistically significant $F(3,277)=$ $74.20, p<.01$. Secure attachment is a significant positive predictor of emotional intelligence, $\beta=57, t(281)=8.98, p$ $<.01$, avoidant attachment, surprisingly, is a significant positive predictor of emotional intelligence, $\beta=.20, t(281)=$ $3.83, p<.01$, and anxious attachment is a significant negative predictor of emotional intelligence, $\beta=-.24, t(281)$ $=-4.11, p<.01$.

Given these results, we can say that the $\mathrm{H} 1$ hypothesis is largely supported by the analyzed data, secure and avoidant attachment are positive predictors and anxious attachment is a negative predictor of emotional intelligence.

For testing the second hypothesis a series of mediation analyzes were performed, having as predictors, alternatively, the three attachment styles, as a dependent variable the emotional intelligence and as mediating variables, alternatively, the three cognitive schemas. The medmod module of Jamovi was used (The jamovi project, 2019).

H2. Cognitive schemas mediates the relationship between attachment styles and emotional intelligence.

$\mathrm{H} 2 \mathrm{a}$. The emotional deprivation cognitive schema mediates the relationship between secure attachment and emotional intelligence.

$\mathrm{H} 2 \mathrm{~b}$. The failure cognitive schema mediates the relationship between secure attachment and emotional intelligence.

$\mathrm{H} 2 \mathrm{c}$. The approval seeking cognitive schema mediates the relationship between secure attachment and emotional intelligence. 
Table 3. Mediation estimates of emotional deprivation schema in the relationship between secure attachment and emotional intelligence

\begin{tabular}{|c|c|c|c|c|c|c|c|c|}
\hline \multirow[b]{2}{*}{ Effect } & \multirow[b]{2}{*}{ Label } & \multirow[b]{2}{*}{ Estimate } & \multirow[b]{2}{*}{ ES } & \multicolumn{3}{|c|}{ 95\% Confidence Interval } & \multirow[b]{2}{*}{$P$} & \multirow[b]{2}{*}{$\%$ Mediation } \\
\hline & & & & Min. & Max. & Z & & \\
\hline Indirect & $a \times b$ & 1.19 & .50 & .20 & 2.17 & 2.36 & .02 & 8.11 \\
\hline Direct & C & 13.45 & 1.29 & 10.93 & 15.98 & 10.43 & .00 & 91.89 \\
\hline Total & $c+a \times b$ & 14.64 & 1.22 & 12.26 & 17.02 & 12.04 & .00 & 100.00 \\
\hline
\end{tabular}

Table 4. Path estimate for emotional deprivation schema in the relationship between secure attachment and emotional intelligence.

\begin{tabular}{rlllllllll}
\hline & & & & & & \multicolumn{2}{c}{$95 \%$ Confidence Interval } & & \\
& & & Label & Estimate & ES & Min. & Max. & Z & P \\
\hline ATS & $\rightarrow$ & SDE & A & -1.68 & .26 & -2.18 & -1.17 & -6.53 & .00 \\
SDE & $\rightarrow$ & IE & B & -.71 & .28 & -1.26 & -.16 & -2.53 & .01 \\
ATS & $\rightarrow$ & IE & C & 13.45 & 1.29 & 10.93 & 15.98 & 10.43 & .00 \\
\hline
\end{tabular}

ATS - Secure attachment, SDE - Emotional deprivation schema, IE - Emotional intelligence

It is observed that emotional deprivation schema mediates the relationship between secure attachment and emotional intelligence, the mediation percentage being $8.11 \%$. The indirect effect is $1.19, \mathrm{Cl} 95 \%(.20,2.17), \mathrm{Z}=2.36, \mathrm{p}<.05$. The secure attachment is significantly and negatively associated with the emotional deprivation schema, $\beta=$ 1.68, $\mathrm{Cl} 95 \%(-2.18,-1.17), \mathrm{Z}=-6.53, \mathrm{p}<.01$ and the emotional deprivation schema is significantly and negatively associated with emotional intelligence, $\beta=-.71$, Cl95\%($1.26,-.16), Z=-2.53, p<.05$.

Table 5. Mediation estimates of failure schema for the relationship between secure attachment and emotional intelligence.

\begin{tabular}{|c|c|c|c|c|c|c|c|c|}
\hline \multirow[b]{2}{*}{ Effect } & \multirow[b]{2}{*}{ Label } & \multirow[b]{2}{*}{ Estimate } & \multirow[b]{2}{*}{ ES } & \multicolumn{2}{|c|}{ 95\% Confidence Interval } & \multirow[b]{2}{*}{ Z } & \multirow[b]{2}{*}{$\mathbf{P}$} & \multirow[b]{2}{*}{$\%$ Mediation } \\
\hline & & & & Min. & Max. & & & \\
\hline Indirect & $a \times b$ & 3.59 & .74 & 2.13 & 5.04 & 4.82 & .00 & 24.5 \\
\hline Direct & C & 11.05 & 1.32 & 8.48 & 13.63 & 8.41 & .00 & 75.5 \\
\hline Total & $c+a \times b$ & 14.64 & 1.22 & 12.26 & 17.02 & 12.04 & .00 & 100.0 \\
\hline
\end{tabular}


Table 6. Path estimate for failure schema in the relationship between secure attachment and emotional intelligence

\begin{tabular}{|c|c|c|c|c|c|c|c|c|c|}
\hline & & & \multirow[b]{2}{*}{ Label } & \multirow[b]{2}{*}{ Estimate } & \multirow[b]{2}{*}{ ES } & \multicolumn{2}{|c|}{ 95\% Confidence Interval } & \multirow[b]{2}{*}{ Z } & \multirow[b]{2}{*}{$\mathrm{F}$} \\
\hline & & & & & & Min. & Max. & & \\
\hline ATS & $\rightarrow$ & SES & a & -2.36 & .26 & -2.86 & -1.86 & -9.22 & .00 \\
\hline SES & $\rightarrow$ & $\mathrm{IE}$ & b & -1.52 & .27 & -2.05 & -.99 & -5.66 & .00 \\
\hline ATS & $\rightarrow$ & $\mathrm{IE}$ & c & 11.05 & 1.32 & 8.48 & 13.63 & 8.41 & .00 \\
\hline
\end{tabular}

ATS - Secure attachment, SES - Failure schema, IE - Emotional intelligence

It is observed that the failure schema mediates the relationship between the secure attachment and the emotional intelligence, the mediation percentage being $24.5 \%$. The indirect effect is $3.59, \mathrm{Cl} 95 \%(2.13,5.04), \mathrm{Z}=$
4.82, $p<.01$. The secure attachment is significantly and negatively associated with the failure schema, $\beta=-2.36$, Cl95\%(-2.86, -1.86), $Z=-9.22, p<.01$ and the failure schema is negatively and significantly associated with emotional intelligence, $\beta=-1.52, \mathrm{Cl} 95 \%(-2.05,-.99), \mathrm{Z}=$ $5.66, p<.01$.

Table 7. Mediation estimates for approval seeking schema in the relationship between secure attachment and emotional intelligence

\begin{tabular}{|c|c|c|c|c|c|c|c|c|}
\hline \multirow[b]{2}{*}{ Effect } & \multirow[b]{2}{*}{ Label } & \multirow[b]{2}{*}{ Estimate } & \multirow[b]{2}{*}{ ES } & \multicolumn{2}{|c|}{ 95\% Confidence Interval } & \multirow[b]{2}{*}{ z } & \multirow[b]{2}{*}{$\mathbf{P}$} & \multirow[b]{2}{*}{$\%$ Mediation } \\
\hline & & & & Min. & Max. & & & \\
\hline Indirect & $a \times b$ & 4.03 & .83 & 2.41 & 5.65 & 4.88 & .00 & 27.5 \\
\hline Direct & C & 10.61 & 1.37 & 7.93 & 13.29 & 7.75 & .00 & 72.5 \\
\hline Total & $c+a \times b$ & 14.64 & 1.22 & 12.26 & 17.02 & 12.04 & .00 & 100.0 \\
\hline
\end{tabular}

Table 8. Path estimates for approval seeking schema in the relationship between secure attachment and emotional intelligence

\begin{tabular}{|c|c|c|c|c|c|c|c|c|c|}
\hline & & & \multirow[b]{2}{*}{ Label } & \multirow[b]{2}{*}{ Estimate } & \multirow[b]{2}{*}{ ES } & \multicolumn{3}{|c|}{ 95\% Confidence Interval } & \multirow[b]{2}{*}{$\mathbf{P}$} \\
\hline & & & & & & Min. & Max. & Z & \\
\hline ATS & $\rightarrow$ & SCA & a & -8.32 & .78 & -9.85 & -6.79 & -10.66 & .00 \\
\hline SCA & $\rightarrow$ & $\mathrm{IE}$ & b & -.49 & .09 & -.66 & -.31 & -5.48 & .00 \\
\hline ATS & $\rightarrow$ & $\mathrm{IE}$ & c & 10.61 & 1.37 & 7.93 & 13.29 & 7.75 & .00 \\
\hline
\end{tabular}

ATS - Secure attachment, SCA- Approval seeking schema, IE - Emotional intelligence

It is observed that the approval seeking schema mediates the relationship between the secure attachment and the emotional intelligence, the mediation percentage being $27.5 \%$. The indirect effect is $4.03, \mathrm{Cl} 95 \%(2.41,5.65), \mathrm{Z}=$ $4.88, p<.01$. The secure attachment is significantly and negatively associated with approval seeking schema, $\beta=$ 8.32, $\mathrm{Cl} 95 \%$ (- 9.85, -6.79), $\mathrm{Z}=-10.66, \mathrm{p}<.01$ and the approval seeking schema is significantly and negatively associated with emotional intelligence, $\beta=-.49$, Cl95\%(-.66, $-.31), Z=-5.48, p<.01$.

The data above shows that cognitive schemas mediate the relationship between secure attachment and emotional intelligence.
$\mathrm{H} 2 \mathrm{~d}$. The emotional deprivation cognitive schema mediates the relationship between avoidant attachment and emotional intelligence.

H2e. The failure cognitive schema mediates the relationship between avoidant attachment and emotional intelligence.

H2f. The approval seeking cognitive schema mediates the relationship between avoidant attachment and emotional intelligence. 
Table 9. Mediation estimates for emotional deprivation schema in the relationship between avoidant attachment and emotional intelligence

\begin{tabular}{|c|c|c|c|c|c|c|c|c|}
\hline \multirow[b]{2}{*}{ Effect } & \multirow[b]{2}{*}{ Label } & \multirow[b]{2}{*}{ Estimate } & \multirow[b]{2}{*}{ ES } & \multicolumn{2}{|c|}{ 95\% Confidence Interval } & \multirow[b]{2}{*}{ Z } & \multirow[b]{2}{*}{$\mathbf{P}$} & \multirow[b]{2}{*}{$\%$ Mediation } \\
\hline & & & & Min. & Max. & & & \\
\hline Indirect & $a \times b$ & -2.10 & .62 & -3.31 & -.89 & -3.41 & .00 & 39.8 \\
\hline Direct & C & -3.17 & 1.56 & -6.24 & -.11 & -2.03 & .04 & 60.2 \\
\hline Total & $c+a \times b$ & -5.28 & 1.57 & -8.36 & -2.19 & -3.35 & .00 & 100.0 \\
\hline
\end{tabular}

Table 10. Path estimates for emotional deprivation schema in the relationship between avoidant attachment and emotional intelligence

\begin{tabular}{|c|c|c|c|c|c|c|c|c|c|}
\hline & & & \multirow[b]{2}{*}{ Label } & \multirow[b]{2}{*}{ Estimate } & \multirow[b]{2}{*}{ ES } & \multicolumn{2}{|c|}{ 95\% Confidence Interval } & \multirow[b]{2}{*}{ Z } & \multirow[b]{2}{*}{$\mathbf{P}$} \\
\hline & & & & & & Min. & Max. & & \\
\hline ATE & $\rightarrow$ & SDE & A & 1.32 & .28 & .76 & 1.87 & 4.63 & .00 \\
\hline SDE & $\rightarrow$ & $\mathrm{IE}$ & B & -1.60 & .32 & -2.22 & -.98 & -5.05 & .00 \\
\hline ATE & $\rightarrow$ & $\mathrm{IE}$ & C & -3.17 & 1.56 & -6.24 & -.11 & -2.03 & .04 \\
\hline
\end{tabular}

ATE - Avoidant attachment, SDE - Emotional deprivation schema, IE - Emotional intelligence

It is observed that the emotional deprivation schema mediates the relationship between avoidant attachment and emotional intelligence, the mediation percentage being $39.8 \%$. The indirect effect is $-2.10, \mathrm{Cl} 95 \%(-3.31,-.89), \mathrm{Z}=$ $-3.41, p<.01$. The avoidant attachment is significantly and positively associated with the emotional deprivation schema, $\beta=1.32$, $\operatorname{Cl} 95 \%(.76,1.87), Z=4.63, p<.01$ and the emotional deprivation schema is significantly and negatively associated with emotional intelligence, $\beta=-1.60$, CI95\%(-2.22, -.98), $Z=-5.05, p<.01$.

Table 11. Mediation estimates for failure schema in the relationship between avoidant attachment and emotional intelligence

95\% Confidence Interval

\begin{tabular}{llrrrrrrr} 
Effect & Label & Estimate & ES & Min. & Max. & Z & p & \% Mediation \\
\hline Indirect & $\mathrm{a} \times \mathrm{b}$ & -5.06 & .94 & -6.89 & -3.23 & -5.41 & .00 & 95.89 \\
Direct & $\mathrm{C}$ & -.22 & 1.49 & -3.13 & 2.70 & -.15 & .88 & 4.11 \\
Total & $\mathrm{C}+\mathrm{a} \times \mathrm{b}$ & -5.28 & 1.57 & -8.36 & -2.19 & -3.35 & .00 & 100.00 \\
\hline
\end{tabular}

Table 12. Path estimates for failure schema in the relationship between avoidant attachment and emotional intelligence.

\begin{tabular}{|c|c|c|c|c|c|c|c|c|c|}
\hline & & & & & & $95 \%$ Co & nce Interval & & \\
\hline & & & Label & Estimate & ES & Min. & Max. & z & $P$ \\
\hline ATE & $\rightarrow$ & SES & a & 1.95 & .29 & 1.38 & 2.52 & 6.71 & .00 \\
\hline SES & $\rightarrow$ & IE & $b$ & -2.59 & .28 & -3.15 & -2.04 & -9.15 & .00 \\
\hline ATE & $\rightarrow$ & IE & c & -.22 & 1.49 & -3.13 & 2.70 & -.15 & .88 \\
\hline
\end{tabular}

ATE - Avoidant attachment, SES - Failure schema, IE - Emotional intelligence

It is observed that the failure schema mediates the relationship between avoidant attachment and emotional intelligence, the mediation percentage being $95.89 \%$. The indirect effect is $-5.06, \mathrm{Cl} 95 \%(-6.89,-3.23), Z=-5.41, p<$ .01 . The avoidant attachment is significantly and positively associated with the failure schema, $\beta=1.95$, Cl95\%(1.38, 2.52), $Z=6.71, p<.01$ and the failure schema is significantly and negatively associated with emotional intelligence, $\beta=$ 2.59, Cl95\%(-3.15, -2.04), Z = -9.15, $p<.01$. 
Table 13. Mediation estimates for approval seeking schema in the relationship between avoidant attachment and emotional intelligence

95\% Confidence Interval

\begin{tabular}{llrrrrrrr} 
Effect & Label & Estimate & ES & Min. & Max. & Z & P & \% Mediation \\
\hline Indirect & $\mathrm{a} \times \mathrm{b}$ & -4.96 & .94 & -6.80 & -3.12 & -5.29 & .00 & 94.00 \\
Direct & $\mathrm{C}$ & -.32 & 1.46 & -3.18 & 2.54 & -.22 & .83 & 6.00 \\
Total & $\mathrm{C}+\mathrm{a} \times \mathrm{b}$ & -5.28 & 1.57 & -8.36 & -2.19 & -3.35 & .00 & 100.00 \\
\hline
\end{tabular}

Table 14. Path estimates for the approval seeking schema in the relationship between avoidant attachment and emotional intelligence

\begin{tabular}{rlllllllll}
\hline & & & & & & \multicolumn{2}{c}{$95 \%$ Confidence Interval } & & \\
\cline { 7 - 8 } & & & Label & Estimate & ES & Min. & Max. & Z & P \\
\hline ATE & $\rightarrow$ & SCA & a & 5.87 & .93 & 4.05 & 7.69 & 6.33 & .00 \\
SCA & $\rightarrow$ & IE & b & -.85 & .09 & -1.02 & -.67 & -9.63 & .00 \\
ATE & $\rightarrow$ & IE & C & -.32 & 1.46 & -3.18 & 2.54 & -.22 & .83 \\
\hline
\end{tabular}

ATE - Avoidant attachment, SCA- Approval seeking schema, IE - Emotional intelligence

It is observed that the approval seeking schema mediates the relationship between avoidant attachment and emotional intelligence, the mediation percentage being $94 \%$. The indirect effect is $-4.96, \mathrm{Cl} 95 \%(-6.80,-3.12), \mathrm{Z}=-5.29, \mathrm{p}<$ .01 . The avoidant attachment is significantly and positively associated with the approval seeking schema, $\beta=5.87$, $\mathrm{Cl} 195 \%(4.05,7.69), Z=6.33, p<.01$ and the approval seeking schema is significantly and negatively associated with emotional intelligence, $\beta=-.85, \mathrm{Cl} 95 \%$ (- 1.02, -.67), Z $=-9.63, p<.01$.
The data above shows that cognitive schemas mediate the relationship between an avoidant attachment and emotional intelligence.

$\mathrm{H} 2 \mathrm{~g}$. The emotional deprivation cognitive schema mediates the relationship between anxious attachment and emotional intelligence.

$\mathrm{H} 2 \mathrm{~h}$. The failure cognitive schema mediates the relationship between anxious attachment and emotional intelligence.

H2i. The approval seeking cognitive schema mediates the relationship between anxious attachment and emotional intelligence.

Table 15. Mediation estimates for the emotional deprivation schema in the relationship between anxious attachment and emotional intelligence

\begin{tabular}{|c|c|c|c|c|c|c|c|c|}
\hline \multirow[b]{2}{*}{ Effect } & \multirow[b]{2}{*}{ Label } & \multirow[b]{2}{*}{ Estimate } & \multirow[b]{2}{*}{ ES } & \multicolumn{3}{|c|}{ 95\% Confidence Interval } & \multirow[b]{2}{*}{$p$} & \multirow[b]{2}{*}{$\%$ Mediation } \\
\hline & & & & Min. & Max. & Z & & \\
\hline Indirect & $a \times b$ & -.66 & .73 & -2.09 & .77 & -.91 & .37 & 6.21 \\
\hline Direct & C & -9.98 & 1.29 & -12.52 & -7.45 & -7.71 & .00 & 93.79 \\
\hline Total & $c+a \times b$ & -10.64 & 1.07 & -12.74 & -8.54 & -9.93 & .00 & 100.00 \\
\hline
\end{tabular}

It is observed that the emotional deprivation schema does not mediate the relationship between anxious attachment and emotional intelligence, the mediation percentage being $6.21 \%, p>.05$. 
Table 16. Mediation estimates for the failure schema in the relationship between anxious attachment and emotional intelligence $95 \%$ Confidence Interval

\begin{tabular}{llrrrrrrr} 
Effect & Label & Estimate & ES & Min. & Max. & Z & p & \% Mediation \\
\hline Indirect & $\mathrm{a} \times \mathrm{b}$ & -3.95 & .82 & -5.56 & -2.34 & -4.82 & .00 & 37.1 \\
Direct & $\mathrm{C}$ & -6.69 & 1.27 & -9.19 & -4.20 & -5.26 & .00 & 62.9 \\
Total & $\mathrm{C}+\mathrm{a} \times \mathrm{b}$ & -10.64 & 1.07 & -12.74 & -8.54 & -9.93 & .00 & 100.0 \\
\hline
\end{tabular}

Table 17. Path estimates for the failure schema in the relationship between anxious attachment and emotional intelligence

\begin{tabular}{|c|c|c|c|c|c|c|c|c|c|}
\hline & & & \multirow[b]{2}{*}{ Label } & \multirow[b]{2}{*}{ Estimate } & \multirow[b]{2}{*}{ ES } & \multicolumn{2}{|c|}{ 95\% Confidence Interval } & \multirow[b]{2}{*}{$z$} & \multirow[b]{2}{*}{$\mathbf{P}$} \\
\hline & & & & & & Min. & Max. & & \\
\hline ATA & $\rightarrow$ & SES & a & 2.42 & .20 & 2.04 & 2.80 & 12.37 & .00 \\
\hline SES & $\rightarrow$ & $\mathrm{IE}$ & $b$ & -1.63 & .31 & -2.24 & -1.02 & -5.23 & .00 \\
\hline ATA & $\rightarrow$ & $\mathrm{IE}$ & c & -6.69 & 1.27 & -9.19 & -4.20 & -5.26 & .00 \\
\hline
\end{tabular}

ATA - Anxious attachment, SES - Failure schema, IE - Emotional intelligence

It is observed that the failure schema mediates the relationship between anxious attachment and emotional intelligence, the mediation percentage being $37.1 \%$. The indirect effect is $-3.95, \mathrm{Cl} 95 \%(-5.56,-2.34), \mathrm{Z}=-4.82, \mathrm{p}<$ .01. The anxious attachment is significantly and positively associated with the failure schema, $\beta=2.42$, Cl95\%(2.04, $2.80), Z=12.37, p<.01$ and failure schema is significantly and negatively associated with emotional intelligence, $\beta=$ 1.63, Cl95\%(-2.24, -1.02$), Z=-5.23, p<.01$.

Table 18. Mediation estimates for approval seeking schema in the relationship between anxious attachment and emotional intelligence

\begin{tabular}{|c|c|c|c|c|c|c|c|c|}
\hline \multirow[b]{2}{*}{ Effect } & \multirow[b]{2}{*}{ Label } & \multirow[b]{2}{*}{ Estimate } & \multirow[b]{2}{*}{ ES } & \multicolumn{2}{|c|}{ 95\% Confidence Interval } & \multirow[b]{2}{*}{ Z } & \multirow[b]{2}{*}{$p$} & \multirow[b]{2}{*}{$\%$ Mediation } \\
\hline & & & & Min. & Max. & & & \\
\hline Indirect & $a \times b$ & -4.98 & 1.12 & -7.17 & -2.80 & -4.47 & .00 & 46.8 \\
\hline Direct & C & -5.66 & 1.49 & -8.59 & -2.73 & -3.79 & .00 & 53.2 \\
\hline Total & $c+a \times b$ & -10.64 & 1.07 & -12.74 & -8.54 & -9.93 & .00 & 100.0 \\
\hline
\end{tabular}

Table 19. Path estimates for approval seeking schema for the relationship between anxious attachment and emotional intelligence

\begin{tabular}{|c|c|c|c|c|c|c|c|c|c|}
\hline & & & \multirow[b]{2}{*}{ Label } & \multirow[b]{2}{*}{ Estimate } & \multirow[b]{2}{*}{ ES } & \multicolumn{2}{|c|}{ 95\% Confidence Interval } & \multirow[b]{2}{*}{ Z } & \multirow[b]{2}{*}{$\mathrm{F}$} \\
\hline & & & & & & Min. & Max. & & \\
\hline ATA & $\rightarrow$ & SCA & $a$ & 9.31 & .53 & 8.27 & 10.36 & 17.49 & .00 \\
\hline SCA & $\rightarrow$ & IE & $b$ & -.54 & .12 & -.76 & -.31 & -4.62 & .00 \\
\hline ATA & $\rightarrow$ & IE & C & -5.66 & 1.49 & -8.59 & -2.73 & -3.79 & .00 \\
\hline
\end{tabular}

ATA - Anxious attachment, SCA- Approval seeking schema, IE - Emotional intelligence

It is observed that the approval seeking schema mediates the relationship between anxious attachment and emotional intelligence, the mediation percentage being $46.8 \%$. The indirect effect is $-4.98, \mathrm{Cl} 95 \%(-7.17,-2.80), \mathrm{Z}=-4.47, \mathrm{p}<$
.01.The anxious attachment is significantly and positively associated with the approval seeking schema, $\beta=9.31$, CI95\%(8.27, 10.36), $Z=17.49, p<.01$ and the approval seeking schema is significantly and negatively associated 
with emotional intelligence, $\beta=-.54, \mathrm{Cl} 95 \%(-.76,-.31), \mathrm{Z}=$ $4.62, p<.01$.

The data above shows that only failure and approval seeking cognitive schemas mediate the relationship between the anxious attachment and emotional intelligence.

\section{DISCUSSION}

The present study aimed to analyse the role of three cognitive schemas (emotional deprivation, failure and approval seeking) in the relationship between the three styles of attachment (anxious, avoidant and secure) and emotional intelligence. The first objective was to establish the relationship between attachment styles and emotional intelligence. Following the results obtained, it was observed that the three styles of attachment are largely responsible for the variation of emotional intelligence (44.6\%), the regression equation being statistically significant. It was also found that both the securing and the avoidant attachment are significant positive predictors of emotional intelligence. This aspect could be explained by the fact that a person with an avoidant attachment style, although he is oriented to keep distance from others when he feels overwhelmed, he understands the emotions of others, but especially his own. Despite the communication problems of this type of attachment (Anders \& Tucker, 2000; Jones, 2005; Egeci \& Gencoz, 2011; Kamel Abbasi et al., 2016; Muetzelfeld et al., 2020), we consider that they act rather as coping mechanism, when the person feels overwhelmed by the desires of others he sees distance as a refuge. The results obtained are supported by the literature, noting that between a style of avoidant attachment and emotional intelligence there is a statistically significant positive relationship (Kafetsios, 2004).

Instead, from the results we can deduce that the anxious attachment is a negative predictor of emotional intelligence. An anxious attachment is distinguished by a high degree of concern and dependence on people (Baldwin \& Fehr, 1995). Also because this insecurity is manifested in social skills we can consider that this aspect could be a reason for low emotional intelligence (Muetzelfeld et al., 2020). It can be stated, therefore, that the $\mathrm{H} 1$ hypothesis is largely supported by the data obtained and subsequently analyzed, so we can say that attachment styles are significant predictors of emotional intelligence.

Following the mediation analyses it was found that there is a mediation between cognitive schemas and the relationship between attachment styles and emotional intelligence, the style of secure attachment being significantly negatively associated with all three types of patterns, as expected. We can deduce that hypotheses $\mathrm{H} 2 \mathrm{a}$, $\mathrm{H} 2 \mathrm{~b}$ and $\mathrm{H} 2 \mathrm{c}$ have been fully confirmed.

In contrast, the results show that an avoidant attachment is significantly associated positively with all three cognitive schemas. We can say that the hypotheses $\mathrm{H} 2 \mathrm{~d}, \mathrm{H} 2 \mathrm{e}$ and $\mathrm{H} 2 \mathrm{f}$ have been fully confirmed. An avoidant attachment style is characterized by a distant behavior towards people around, as well as a low sense of security, which amplifies dysfunctional thoughts. Also, numerous studies in the literature have shown that for an attachment that is not secure, dealing with problematic situations is more difficult and longer lasting (Gay et al., 2013; Langhinrichsen-Rohling et al., 2017; Kaya \& Aydin, 2021). For dysfunctional attachments, a traumatic experience will have a deeper effect, people being stuck in those events. They will use denial or avoidance mechanisms to deal with these stressful situations, but they will amplify the negative states experienced prolonging the healing process (Lussier et al., 1997; Howard \& Medway, 2004).

Regarding the anxious attachment, the hypotheses have not been fully confirmed. The mediation of emotional deprivation schema in the relationship between anxiety attachment style and emotional intelligence was not statistically significant, so the $\mathrm{H} 2 \mathrm{~g}$ hypothesis was not confirmed. In contrast, the relationship between anxiety attachment and cognitive schemas was significant positive, so $\mathrm{H} 2 \mathrm{~h}$ and $\mathrm{H} 2 \mathrm{i}$ hypotheses were confirmed. An anxious attachment tends to be dependent on those around him and to depend on them and he will believe that their abandonment will bring them failure, amplifying the cognitive schema of failure. Also, the fear of abandonment experienced by people with an anxious attachment will translate into the constant need for validation and approval from others, just to calm their negative feelings (Mikulincer \& Shaver, 2007).

\section{Limitations and further directions}

A limitation of this study is the use of self-reporting tools, through which the sample formed answered the given questionnaire, choosing the most appropriate answer for them on a six- and five-step Likert scale. As a direction for the future, answers could be collected from people close to the subjects, to help maintaining the validity of the data obtained.

Another limitation of the study is the composition of the group of participants, who are predominantly female. This aspect prevents the generalization of the result, but also the realization of a comparative analysis according to gender. Also, the data were collected from participants established only in Romania, which would prevent, again, a generalization of the results obtained. In attempting to replicate the study, this limitation should be taken into account, recommending a balance in the group of participants, as well as data collection on a larger scale.

Also, another limitation of the study could be the low number of articles on cognitive schemas, as well as their relationship with other variables. The questionnaire used for attachment styles was not validated on the Romanian population, so the data obtained were quite difficult to extract. As future directions, we can encourage the use of other assessment tools or its validation on the Romanian population. 


\section{REFERENCES}

Ak, M., Lapsekili, N., Haciomeroglu, B., Sutcigil, L., \& Turkcapar, H. (2012). Early maladaptive schemas in bipolar disorder: Schemas in bipolar disorder. Psychology and Psychotherapy: Theory, Research and Practice, 85(3), 260-267. $\quad$ https://doi.org/10.1111/j.20448341.2011.02037.x

Anders, S. L., \& Tucker, J. S. (2000). Adult attachment style, interpersonal communication competence, and social support. Personal Relationships, 7(4), 379-389. https://doi.org/10.1111/j.1475-6811.2000.tb00023.x

Baldwin, M. W., \& Fehr, B. (1995). On the instability of attachment style ratings. Personal Relationships, 2(3), 247-261. $\quad$ https://doi.org/10.1111/j.1475-6811.1995. tb00090.x

Ball, S. A. (2007). Cognitive-behavioural and schema-based models for the treatment of substance use disorders. In L. P. Riso, P. L. du Toit, D. J. Stein, \& J. E. Young (Eds.), Cognitive schemas and core beliefs in psychological problems: A scientist practitioner guide (pp. 111-138). Washington, DC: American Psychological Association.

Beck, A. T., \& Weishaar, M. (2005). Cognitive therapy. In R. J. Corsini \& D. Wedding (Eds.), Current psychotherapies (p. 238-268). Thomson Brooks/Cole Publishing Co.

Beck, A. T., \& Haigh, E. A. P. (2014). Advances in Cognitive Theory and Therapy: The Generic Cognitive Model. Annual Review of Clinical Psychology, 10(1), 1-24. https://doi.org/10.1146/annurev-clinpsy-032813-153734

Beck, A. T., Rush, A. J., Shaw, B. F., \& Emery, G. (1979). Cognitive Therapy of Depression. New York: Guilford.

Beck, J. S. (1995). Cognitive Therapy: Basics and Beyond. New York: Guilford.

Bosmans, G., Bakermans-Kranenburg, M. J., Vervliet, B., Verhees, M. W. F. T., \& van IJzendoorn, M. H. (2020). A learning theory of attachment: Unraveling the black box of attachment development. Neuroscience \& Biobehavioral Reviews, 113, 287-298. https://doi.org/10.1016/j.neubiorev.2020.03.014

Bosmans, G., Braet, C., \& Van Vlierberghe, L. (2010). Attachment and symptoms of psychopathology: Early maladaptive schemas as a cognitive link? Clinical Psychology \& Psychotherapy, 17(5), 374-385. https://doi.org/10.1002/cpp.667

Bowlby, J. (1982). Attachment and loss: Retrospect and prospect. American Journal of Orthopsychiatry, 52(4), 664678. https://doi.org/10.1111/j.1939-0025.1982.tb01456.x

Bowlby, J. (1988). A Secure Base: Parent-Child Attachment and Healthy Human Development. New York: Basic Books. Caltabiano, M. L., \& Grosset, C. (2009). Attachment, Coping and Life Satisfaction amongst Tertiary Students.

Cherniss, C., Extein, M., Goleman, D., \& Weissberg, R. P. (2006). Emotional Intelligence: What Does the Research Really Indicate? Educational Psychologist, 41(4), 239-245. https://doi.org/10.1207/s15326985ep4104_4

Clark, D. A., Beck, A. T., \& Alford, B. A. (1999). Scientific Foundations of Cognitive Theory and Therapy of Depression. Philadelphia, PA: Wiley.
Dimitriu, O., \& Negrescu, M. (2015). Emotional Intelligence and the Tendency to Use Dysfunctional Cognitive Schemas. Procedia - Social and Behavioral Sciences, 187, 301-306. https://doi.org/10.1016/j.sbspro.2015.03.056

DiTommaso, E., Brannen-McNulty, C., Ross, L., \& Burgess, M. (2003). Attachment styles, social skills and loneliness in young adults. Personality and Individual Differences, 35(2), $303-312$.

8869(02)00190-3

https://doi.org/10.1016/S0191-

Doinita, N. E. (2015). Adult Attachment, Self-esteem and Emotional Intelligence. Procedia - Social and Behavioral Sciences, $\quad 187, \quad 570-574$. https://doi.org/10.1016/j.sbspro.2015.03.106

Dozois, D. J. A., \& Beck, A. T. (2008). Cognitive Schemas, Beliefs and Assumptions. In Risk Factors in Depression (pp. 119-143). Elsevier. https://doi.org/10.1016/B978-0-08045078-0.00006-X

Egeci, I. S., \& Gencoz, T. (2011). The Effects of Attachment Styles, Problem-Solving Skills, and Communication Skills on Relationship Satisfaction. Procedia - Social and Behavioral Sciences, $\quad 30, \quad 2324-2329$. https://doi.org/10.1016/j.sbspro.2011.10.453

Esmali Kooraneh, A., \& Amirsardari, L. (2015). Predicting Early Maladaptive Schemas Using Baumrind's Parenting Styles. Iranian Journal of Psychiatry and Behavioral Sciences, 9(2). https://doi.org/10.17795/ijpbs952

Fischer, T. D., Smout, M. F., \& Delfabbro, P. H. (2016). The relationship between psychological fexibility, early maladaptive schemas, perceived parenting and psychopathology. Journal of Contextual Behavioral Science, 5(3), 169-177. https://doi.org/10.1016/j.jcbs.2016.06.002 Fouladi, M. (2015). Prediction of depression through early maladaptive schemas. Mediterranean Journal of Social Sciences, 6(1), 602-611. https://doi.org/10.5901/mjss.2015.v6n1s1p602

Gay, L. E., Harding, H. G., Jackson, J. L., Burns, E. E., \& Baker, B. D. (2013). Attachment Style and Early Maladaptive Schemas as Mediators of the Relationship between Childhood Emotional Abuse and Intimate Partner Violence. Journal of Aggression, Maltreatment \& Trauma, 22(4), 408424. https://doi.org/10.1080/10926771.2013.775982

Goleman, D. (2012). Emotional Intelligence: Why It Can Matter More Than IQ. Random House Publishing Group.

Goleman, D., Boyatzis, R. E., \& McKee, A. (2013). Primal Leadership: Unleashing the Power of Emotional Intelligence. Harvard Business Press.

Goleman, D., Boyatzis, R., \& McKee, A. (2002). The emotional reality of teams. Journal of Organizational Excellence, 21(2), 55-65. https://doi.org/10.1002/npr.10020 Greenberg, M. T., Siegel, J. M., \& Leitch, C. J. (1983). The nature and importance of attachment relationships to parents and peers during adolescence. Journal of Youth and Adolescence, 12(5), 373-386. https://doi.org/10.1007/BF02088721

Grewal, D., \& Salovey, P. (2005). Feeling Smart: The Science of Emotional Intelligence: A new idea in psychology has matured and shows promise of explaining how attending 
to emotions can help us in everyday life. American Scientist, 93(4), 330-339.

Harris, A. E., \& Curtin, L. (2002). Parental Perceptions, Early Maladaptive Schemas, and Depressive Symptoms in Young Adults. Cognitive Therapy and Research, 26(3), 405-416. https://doi.org/10.1023/A:1016085112981

Hawkins, A. C., Howard, R. A., \& Oyebode, J. R. (2007). Stress and coping in hospice nursing staff. The impact of attachment styles. Psycho-Oncology, 16(6), 563-572. https://doi.org/10.1002/pon.1064

Howard, M. S., \& Medway, F. J. (2004). Adolescents' attachment and coping with stress. Psychology in the Schools, 41(3), 391-402. https://doi.org/10.1002/pits.10167 IBM Corp. (2013) IBM SPSS Statistics for Windows, Version 22.0. IBM Corp., Armonk, NY.

Ingram, R. E. (2003). Origins of cognitive vulnerability to depression. Cognitive Therapy and Research, 27, 77 - 88. Janssen, C. G. C., Schuengel, C., \& Stolk, J. (2002). Understanding challenging behaviour in people with severe and profound intellectual disability: A stressattachment model. Journal of Intellectual Disability Research, 46(6), 445-453. https://doi.org/10.1046/j.13652788.2002.00430.x

Jones, S. M. (2005). Attachment Style Differences and Similarities in Evaluations of Affective Communication Skills and Person-centered Comforting Messages. Western Journal of Communication, 69(3), 233-249. https://doi.org/10.1080/10570310500202405

Kafetsios, K. (2004). Attachment and emotional intelligence abilities across the life course. Personality and Individual Differences, 37(1), 129-145. https://doi.org/10.1016/j.paid.2003.08.006

Kamel Abbasi, A. R., Tabatabaei, S. M., Aghamohammadiyan Sharbaf, H., \& Karshki, H. (2016). Relationship of Attachment Styles and Emotional Intelligence With Marital Satisfaction. Iranian Journal of Psychiatry and Behavioral Sciences, 10(3). https://doi.org/10.17795/ijpbs-2778

Kawamoto, T. (2020). The moderating role of attachment style on the relationship between self-concept clarity and self-esteem. Personality and Individual Differences, 152, 109604. https://doi.org/10.1016/j.paid.2019.109604

Kaya, Y., \& Aydin, A. (2021). The Mediating Role of Early Maladaptive Schemas in the Relationship Between Attachment and Mental Health Symptoms of University Students. Journal of Adult Development, 28(1), 15-24. https://doi.org/10.1007/s10804-020-09352-2

Ke, T., \& Barlas, J. (2020). Thinking about feeling: Using trait emotional intelligence in understanding the associations between early maladaptive schemas and coping styles. Psychology and Psychotherapy: Theory, Research and Practice, 93(1), 1-20. https://doi.org/10.1111/papt.12202

Kim, J. U., \& Kishore, R. (2019). Do we Fully Understand Information Systems Failure? An Exploratory Study of the Cognitive Schema of IS Professionals. Information Systems Frontiers 21(6), 1385-1419.
Kuiper, N. A., \& Olinger, L. J. (1986). Dysfunctional attitudes and a self-worth contingency model of depression. In P. C. Kendall (Ed.), Advances in Cognitive-Behavioral Research and Therapy (Vol. 5, pp. 115 - 142). New York: Academic Press.

Láng, A. (2015). Machiavellianism and early maladaptive schemas in adolescents. Personality and Individual Differences, 87, 162-165. https://doi.org/10.1016/j.paid.2015.07.039

Langhinrichsen-Rohling, J., Thompson, K., Selwyn, C., Finnegan, H., \& Misra, T. (2017). Maladaptive schemas mediate poor parental attachment and suicidality in college students. Death Studies, 41(6), 337-344. https://doi.org/10.1080/07481187.2017.1280714

Ledoux, T., Winterowd, C., Richardson, T., \& Clark, J. D. (2010). Relationship of negative self-schemas and attachment styles with appearance schemas. Body Image, 7(3), 213-217.

https://doi.org/10.1016/j.bodyim.2010.02.003

Leung, P. W. L., \& Poon, M. W. L. (2001). Dysfunctional Schemas and Cognitive Distortions in Psychopathology: A Test of the Specificity Hypothesis. Journal of Child Psychology and Psychiatry, 42(6), 755-765. https://doi.org/10.1111/1469-7610.00772

Lieberman, A. F., \& Zeanah, C. H. (1995). Disorders of Attachment in Infancy. Child and Adolescent Psychiatric Clinics of North America, 4(3), 571-587. https://doi.org/10.1016/S1056-4993(18)30420-6

Lopez, F. G., Mauricio, A. M., Gormley, B., Simko, T., \& Berger, E. (2001). Adult Attachment Orientations and College Student Distress: The Mediating Role of Problem Coping Styles. Journal of Counseling \& Development, 79(4), 459-464. $\quad$ https://doi.org/10.1002/j.15566676.2001.tb01993.x

Lussier, Y., Sabourin, S., \& Turgeon, C. (1997). Coping Strategies as Moderators of the Relationship between Attachment and Marital Adjustment. Journal of Social and Personal Relationships, 14(6), 777-791. https://doi.org/10.1177/0265407597146004

Lyons-Ruth, K., \& Jacobvitz, D. (2008). Attachment Disorganization: Genetic factors, parenting contexts and developmental transformations from infancy to adulthood.

Mayer, J. D., Caruso, D. R., \& Salovey, P. (1999). Emotional intelligence meets traditional standards for an intelligence. Intelligence, 27(4), 267-298. https://doi.org/10.1016/S0160- 2896(99)00016-1

McCarthy, C. J., Moller, N. P., \& Fouladi, R. T. (2001). Continued Attachment to Parents: Its Relationship to Affect Regulation and Perceived Stress Among College Students. Measurement and Evaluation in Counseling and Development, 33(4), 198-213. https://doi.org/10.1080/07481756.2001.12069011

Meyer, B., \& Pilkonis, P. A. (2001). Attachment style. Psychotherapy: Theory, Research, Practice, Training, 38(4), 466-472. https://doi.org/10.1037/0033-3204.38.4.466

Mikulincer, M., \& Shaver, P.R. (2007). Attachment in adulthood: Structure, dynamics, and change. New York: Guilford Press 
Mikulincer, M., \& Shaver, P. R. (2007). Boosting Attachment Security to Promote Mental Health, Prosocial Values, and Inter-Group Tolerance. Psychological Inquiry, 18(3), 139156. https://doi.org/10.1080/10478400701512646

Mikulincer, M., \& Shaver, P. R. (2009). An attachment and behavioral systems perspective on social support. Journal of Social and Personal Relationships, 26(1), 7-19. https://doi.org/10.1177/0265407509105518

Mikulincer, M., \& Shaver, P. R. (2012). Attachment Theory Expanded: A Behavioral Systems Approach. In K. Deaux \& M. Snyder (Eds.), The Oxford Handbook of Personality and Social Psychology (pp. 466-492). Oxford University Press.

https://doi.org/10.1093/oxfordhb/9780195398991.013.0019 Mikulincer, M., \& Shaver, P. R. (2012). Adult Attachment Orientations and Relationship Processes. Journal of Family Theory \& Review, 4(4), 259-274. https://doi.org/10.1111/j.1756-2589.2012.00142.x

Muetzelfeld, H., Megale, A., \& Friedlander, M. L. (2020). Problematic Domains of Romantic Relationships as a Function of Attachment Insecurity and Gender. Australian and New Zealand Journal of Family Therapy, 41(1), 80-90. https://doi.org/10.1002/anzf.1401

Ninivaggi, F. J. (2020). Emotional Intelligence and Mindfulness. In Learned Mindfulness (pp. 47-71). Elsevier. https://doi.org/10.1016/B978-0-12-816484-6.00003-8

Obeid, S., Haddad, C., Akel, M., Fares, K., Salameh, P., \& Hallit, S. (2019). Factors associated with the adults' attachment styles in Lebanon: The role of alexithymia, depression, anxiety, stress, burnout, and emotional intelligence. Perspectives in Psychiatric Care, 55(4), 607617. https://doi.org/10.1111/ppc.12379

Pellerone, M., Iacolino, C., Mannino, G., Formica, I., \& Zabbara, S. (2017). The influence of parenting on maladaptive cognitive schema: A cross-sectional research on a group of adults. Psychology Research and Behavior Management, Volume 10, 47-58. https://doi.org/10.2147/PRBM.S117371

Petrocelli, J. V., Glaser, B. A., Calhoun, G. B., \& Campbell, L. F. (2001). Early Maladaptive Schemas of Personality Disorder Subtypes. Journal of Personality Disorders, 15(6), 546-559. https://doi.org/10.1521/pedi.15.6.546.19189

Pinto-Gouveia, J., Castilho, P., Galhardo, A., \& Cunha, M. (2006). Early Maladaptive Schemas and Social Phobia. Cognitive Therapy and Research, 30(5), 571-584. https://doi.org/10.1007/s10608-006-9027-8

Roelofs, J., Onckels, L., \& Muris, P. (2013). Attachment Quality and Psychopathological Symptoms in Clinically Referred Adolescents: The Mediating Role of Early Maladaptive Schema. Journal of Child and Family Studies, 22(3), 377-385. https://doi.org/10.1007/s10826-012-9589$\mathrm{x}$

Romaniello, C., Farinelli, M., Matera, N., Bertoletti, E., Pedone, V., \& Northoff, G. (2015). Anxious attachment style and hopelessness as predictors of burden in caregivers of patients with disorders of consciousness: A pilot study. Brain Injury, 29(4), 466-472. https://doi.org/10.3109/02699052.2014.989402
Salovey, P., \& Grewal, D. (2005). The Science of Emotional Intelligence. Current Directions in Psychological Science, 14(6), 281-285. https://doi.org/10.1111/j.09637214.2005.00381.x

Salovey, P., \& Mayer, J. D. (1990). Emotional Intelligence. Imagination, Cognition and Personality, 9(3), 185-211. https://doi.org/10.2190/DUGG-P24E-52WK-6CDG

Samadi, R. G., kasaei, F., \& Pour, E. M. (2013a). Attachment Styles as a Predictor of Emotional Intelligence. Procedia - Social and Behavioral Sciences, 84, 1712-1715. https://doi.org/10.1016/j.sbspro.2013.07.018

Schmidt, N. B., Joiner, T. E., Young, J. E., \& Telch, M. J. (1995). The schema questionnaire: Investigation of psychometric properties and the hierarchical structure of a measure of maladaptive schemas. Cognitive Therapy and Research, 19(3), https://doi.org/10.1007/BF02230402

Scott, R. L., \& Cordova, J. V. (2002). The influence of adult attachment styles on the association between marital adjustment and depressive symptoms. Journal of Family Psychology, 16(2), 199-208. https://doi.org/10.1037/0893-3200.16.2.199

Shorey, R. C., Anderson, S. E., \& Stuart, G. L. (2012). Gender Differences in Early Maladaptive Schemas in a Treatment-Seeking Sample of Alcohol-Dependent Adults. Substance Use \& Misuse, 47(1), 108-116. https://doi.org/10.3109/10826084.2011.629706

Terzi, Ş. (2013). Secure attachment style, coping with stress and resilience among university students. 14.

The jamovi project (2021). jamovi. (Version 1.6) [Computer Software]. Retrieved from https://www.jamovi.org

Theisen, J. C., Fraley, R. C., Hankin, B. L., Young, J. F., \& Chopik, W. J. (2018). How do attachment styles change from childhood through adolescence? Findings from an accelerated longitudinal Cohort study. Journal of Research in Personality, 74, 141-146. https://doi.org/10.1016/j.jp.2018.04.001

Wei, M., Heppner, P. P., \& Mallinckrodt, B. (2003). Perceived coping as a mediator between attachment and psychological distress: A structural equation modeling approach. Journal of Counseling Psychology, 50(4), 438447. https://doi.org/10.1037/0022-0167.50.4.438

Wijk-Herbrink, M. F. V., Bernstein, D. P., Broers, N. J., Roelofs, J., Rijkeboer, M. M., \& Arntz, A. (2018). Internalizing and externalizing behaviors share a common predictor: The efects of early maladaptive schemas are mediated by coping responses and schema modes. Journal of Abnormal Child Psychology, 46, 907-920. https://doi.org/10.1007/s10802-017-0386-2.

Yoosefi, N., Etemadi, O., Bahrami, F., Fatehizade, M. A.-S., \& Ahmadi, S. A. (2010). An Investigation on Early Maladaptive Schema in Marital Relationship as Predictors of Divorce. Journal of Divorce \& Remarriage, 51(5), 269-292. https://doi.org/10.1080/10502551003651951

Young, J. E. (1994). Cognitive therapy for personality disorders: A schema-focused approach. Sarasota: Professional Resource Press. 
Young, J. E. (1999). Cognitive Therapy for Personality Disorders: A Schema-Focused Approach (3rd ed.). Sarasota, FL: Professional Resource Press.

Young, J. E., \& Brown, G. (2003). Young schema questionnaire. New York: Cognitive Therapy Center of New York.
Young, J. E., Klosko, J. S., \& Weishaar, M. E. (2003). Schema Therapy: A Practitioner's Guide. New York: Guilford.

Zeigler-Hill, V., Green, B. A., Arnau, R. C., Sisemore, T. B., \& Myers, E. M. (2011). Trouble ahead, trouble behind: Narcissism and early maladaptive schemas. Journal of Behavior Therapy and Experimental Psychiatry, 42(1), 96103. https://doi.org/10.1016/j.jbtep.2010.07.004. 